\title{
Comportamento de variáveis climáticas em sistemas de ventilação mínima para produção de pintos de corte
}

\author{
Irene Menegali', Ilda F. F. Tinoco ${ }^{2}$, Cinara da C. S. Carvalho ${ }^{3}$, \\ Cecília de F. Souza ${ }^{2} \&$ José H. Martins ${ }^{2}$
}

\begin{abstract}
RESUMO
Durante o processo de criação de frangos de corte a fase inicial ou fase de aquecimento se caracteriza por ser este o período mais delicado devido à imaturidade fisiológica das aves. Desta forma, os fatores ambientais se destacam por inferir, de forma direta, no crescimento, no desempenho zootécnico e na mantança da vida desses animais. Objetivou-se, com base nessas considerações estudar, com este trabalho, o efeito de três diferentes sistemas de ventilação mínima (por pressão positiva, negativa e natural) sobre as variáveis ambientais (temperatura do ar, umidade relativa e velocidade do ar) de galpões de frangos de corte, durante a fase de aquecimento. De acordo com os resultados verificou-se que o sistema de aquecimento utilizado não foi satisfatório para manter a temperatura do ar e a umidade relativa dentro de padrões considerados adequados, expondo as aves, assim, a períodos de estresse térmico por frio. Em contrapartida, não ocorreram influências negativas em relação às taxas de ventilação aplicadas para os dois sistemas de ventilação positiva e negativa. A velocidade do ar também se manteve em níveis considerados não estressores para as aves, no período de aquecimento.
\end{abstract}

Palavras-chave: ambiência, sistemas de aquecimento, renovação do ar, pintinhos

\section{Behavior of environmental variables on minimum ventilation systems for the production of broiler chickens}

\begin{abstract}
During the creation process of poultry, the initial or heating phase, is characterized as the most delicate period due to physiological immaturity of the birds. Thus, environmental factors stand out to infer, directly, in the growth, on the performance and maintenance of life of these animals. Based on these considerations, the aim of this study was to study the effect of three different systems of minimum ventilation (positive pressure, negative and natural) on environmental variables (air temperature, relative humidity and wind velocity) of broiler sheds during the heating phase. According to results obtained, it was verified that the heating system used was inadequate to maintain the air temperature and relative humidity within the standards deemed appropriate, thus exposing the birds to periods of heat stress by cold. In contrast, there were negative influences regarding ventilation rates applied to the two ventilation systems positive and negative. Wind velocity also remained at levels considered non-stressful for young chickens.
\end{abstract}

Key words: ambience, heating systems, air ventilation, young chickens

1 UFMG, Av. Universitária, 1.000, Bairro Universitário, CEP 39.404-547, Montes Claros, MG. E-mail: imenegali@yahoo.com.br

${ }^{2}$ UFV, Avenida P.H. Rolfs, s/n, Centro, CEP 36570-000, Viçosa, MG. Fone: (31) 3899-2729. E-mail: iftinoco@ufv.br; cfsouza@ufv.br; j.helvecio.ma rtins@gmail.com

${ }^{3}$ UNIMONTES, Av. Reinaldo Viana, 2630, Bico da Pedra, CEP 39440-000, Janaúba, MG. Fone: (38) 3821-1378. E-mail: cinara.carvalho@unimontes.br 


\section{INTRODUÇÃO}

O pintinho recém-nascido possui dificuldades na retenção do calor corporal, pelo fato de sua capacidade de termorregulação não estar bem desenvolvida. Assim, as aves jovens ( 1 a 14 dias) necessitam estar inseridas em ambientes com temperatura de aproximadamente $35^{\circ} \mathrm{C}$ para manter sua temperatura corporal constante (Cordeiro et al., 2011). Desta forma, torna-se necessário, para a maioria do território brasileiro, promover o aquecimento das aves nas duas primeiras semanas de vida e, em condições mais rigorosas, necessita-se estender o aquecimento artificial até os 21 dias de vida (Zanatta et al., 2008).

De acordo com Abreu \& Abreu (2002) os aquecedores mais utilizados no Brasil fazem uso de lenha como fonte de calor, em campânula ou fornalha, posicionados no interior de aviários ou externamente, insuflando o ar aquecido para seu interior. Contudo, esses sistemas não produzem temperaturas constantes e, muitas vezes, excedem o necessário e ainda requerem maior mão-de-obra. Sendo assim, é sumamente importante, para a produção animal, de maneira geral, que sejam concebidos projetos mais eficientes de aquecimento sem comprometimento da qualidade do ar visando diminuir o consumo de energia e uniformizar a temperatura nas primeiras semanas de vida das aves (Martin et al., 2006; Menegali et al., 2009; Santos et al., 2009; Vigoderis et al., 2010).

Associada ao uso de aquecedores, nesta fase da vida das aves a ventilação possui papel de grande relevância devido à renovação de ar que deve ocorrer de forma mínima, para que não ocasione redução da temperatura no interior do aviário nem comprometa a saúde dos animais (Zanatta et al., 2008; Vigoderis et al., 2010; Cordeiro et al., 2011).

Os efeitos combinados das variáveis ambientais, como temperatura, umidade e velocidade do ar, taxa de ventilação e concentração de partículas, gases e micro-organismo no ar, determinam a qualidade ambiental nas instalações avícolas e sua influência na qualidade de vida das aves (Banhazi et al., 2008; Saraz et al., 2010).

Com base nessas considerações objetivou-se, neste trabalho, estudar o efeito de três diferentes sistemas de ventilação mínima (por pressão positiva, negativa e natural) sobre as variáveis ambientais (temperatura do ar, umidade relativa e velocidade do ar) de galpões de frangos de corte, durante a fase de aquecimento.

\section{Material e MÉTOdos}

O trabalho foi realizado em três aviários de frangos de corte similares de um mesmo núcleo produtivo, pertencentes a um sistema de integração de empresa comercial, representativa de grande parte da avicultura industrial do Brasil, durante os meses de julho e agosto de 2008.

A coleta de dados experimentais foi realizada na área de crescimento inicial dos frangos de corte, situada no interior dos galpões avícolas e denominada pinteiro, compreendendo o período de 1 a 21 dias, correspondentes ao período de aquecimento nas três primeiras semanas de vida das aves.

Cada galpão foi equipado com um tipo de sistema de ventilação mínima (negativa, natural e positiva) no intuito de renovar o ar e promover uma ventilação higiênica, realizada principalmente na época do inverno.

O sistema de ventilação mínima positiva (SVMP) foi constituído por um ventilador axial, acionado e desligado com uso de temporizadores; foi posicionado na linha do forro, com fluxo no sentido vertical sobre defletor de $1,5 \mathrm{~m}$ de diâmetro.

Para o sistema de ventilação por pressão negativa foi utilizado um exaustor. Este sistema de ventilação mínima foi posicionado na face lateral do galpão, em antessala que antecede o ambiente de pinteiro, o qual foi protegido por cortinas laterais, visando diminuir o espaço a ser aquecido.

O sistema de ventilação mínima via natural ocorreu através do manejo de cortinas e também pela própria abertura das portas quando da entrada dos trabalhadores durante as vistorias.

O funcionamento intermitente dos sistemas de ventilação mínima no interior dos galpões seguiu a recomendação estabelecida pela ASAE (Annual International Meeting) e adaptado de acordo com ilustrado na Tabela 1.

Tabela 1. Programação do período de funcionamento dos sistemas de ventilação mínima para os sistemas de pressão negativa (SVMN) e pressão positiva (SVMP) para a fase de aquecimento

\begin{tabular}{|c|c|c|c|}
\hline \multirow{2}{*}{ Semana } & Tempo ligado & Tempo desligado & \multirow{2}{*}{ Renovação } \\
\hline & \multicolumn{2}{|c|}{$(\min )^{*}$} & \\
\hline Primeira & 1 & 10 & 6 min ligados em $1 \mathrm{~h}$ \\
\hline Segunda & 1 & 8 & $7 \mathrm{~min}$ ligados em $1 \mathrm{~h}$ \\
\hline Terceira & 1 & 7 & $8 \mathrm{~min}$ ligados em $1 \mathrm{~h}$ \\
\hline
\end{tabular}

Os sistemas de aquecimento foram dispostos conforme manejo habitual da empresa, sendo uma campânula a carvão para cada 3000 aves jovens. Na fase inicial de aquecimento as aves foram confinadas em área correspondente a $1 / 3$ do total da área do galpão $(8,6 \mathrm{~m}$ de largura e $28 \mathrm{~m}$ de comprimento e 2,45 de altura) denominada pinteiro ou área de crescimento inicial, situado em uma das extremidades do aviário. Este espaço foi protegido com divisórias internas formando círculos de proteção, isolados por paredes divisórias em fibras de madeira prensada (folhas de eucatex) e por cortinas confeccionadas em fibras de plástico (polietileno) para reduzir o volume de ar a ser aquecido. Inicialmente, cada círculo de proteção possuía cerca de $7 \mathrm{~m}$ de diâmetro e circundava uma campânula. A altura do pinteiro foi compreendida entre o piso e o forro de polietileno. Na medida em que os pintinhos foram se desenvolvendo ocorreu a ampliação adequada desta área e volume.

No primeiro dia de alojamento a densidade foi de 80 aves por $\mathrm{m}^{2}$ (volume de ar de 589,96 $\mathrm{m}^{3}$ ), com ampliação de $3 \mathrm{~m}$ no sentido do comprimento do pinteiro, correspondente ao incremento de mais $63,21 \mathrm{~m}^{3}$ de ar no interior do pinteiro a cada dois dias atingindo, ao final de 21 dias de idade das aves, toda a extensão do galpão.

Foram distribuídas três campânulas de aquecimento a lenha, de maneira a manter a uniformidade no aquecimento total da área de crescimento. $\mathrm{O}$ abastecimento das campânulas foi manual acompanhando as exigências ambientais das aves. $\mathrm{O}$ sensor de temperatura foi posicionado a nível das aves.

Para medição da temperatura e da umidade relativa do ar foram utilizados sensores acoplados a um sistema de aquisição 
de dados de temperatura e umidade, marca Hobo ${ }^{\circledR}$, modelo RH/ Temp H08-032-08, com resolução de $0,1{ }^{\circ} \mathrm{C}$ (temperatura) e $1 \%$ (umidade) e precisão de $\pm 0,7{ }^{\circ} \mathrm{C}$ (temperatura) e $\pm 1 \%$ (umidade). Para a velocidade do ar utilizaram-se instrumentos de anemômetro digital de fio quente, FMA-900-V, marca Ômega, faixa de 0 a $0,51 \mathrm{~m} \mathrm{~s}^{-1}$, precisão de $\pm 2 \%$ na temperatura de 0 a $50{ }^{\circ} \mathrm{C}$. O sinal de saída do equipamento é de 0 a $5 \mathrm{~V}$ e fonte de alimentação de 15 a $24 \mathrm{~V}$.

Com vista à verificação dos dados de velocidade do ar utilizaram-se módulos de entrada analógica, modelo IP-7017. A conexão do anemômetro ao módulo foi feita por cabos telefônicos trançados FI $2 \times 0,24 \mathrm{~mm}^{2}$. Os dados coletados foram armazenados diariamente em arquivos de formato texto, por meio de um programa computacional desenvolvido na linguagem de programação $\mathrm{C}++$ Builder versão 6.0

Para a coleta de dados climáticos do ambiente externo foi utilizado abrigo meteorológico instalado nas proximidades das instalações, a uma altura aproximada de 1,5 m e com sua frente voltada para a face sul.

No interior do abrigo foram instalados sensores para a medição contínua da temperatura e umidade do ar, durante todo o período experimental, equipados pelo mesmo sistema de aquisição de dados utilizados e especificados no interior dos aviários.

Nas proximidades do abrigo, a mais ou menos $1 \mathrm{~m}$ de raio e a $1,5 \mathrm{~m}$ de altura, foi instalado um globo negro para aquisição de temperaturas de globo externas. Para a obtenção das temperaturas de globo negro foram utilizados sensores acoplados a um sistema de aquisição de dados inseridos internamente no centro geométrico dos globos. Nesses mesmos pontos também foram verificados os valores de velocidades do ar.

Para avaliar as variáveis referentes ao ambiente (temperatura e velocidade do ar e a umidade relativa) conduziu-se este experimento em delineamento em blocos casualizados (DBC) em esquema de parcelas subdivididas no tempo tendo-se, nas parcelas, os tratamentos: ventilação mínima por pressão negativa (SVMN), ventilação mínima por pressão positiva (SVMP) e ventilação por via natural (SVMNat) e, nas subparcelas, o tempo (dias da semana). Nesta análise foram considerados repetições os horários nos quais as variáveis foram medidas. Essas variáveis ambientais foram submetidas à análise de variância e as médias comparadas por meio do teste de Tukey adotando-se o nível de 5\% de probabilidade, pelo programa $\mathrm{SAS}^{\circledR}$ System.

\section{Resultados E Discussẽo}

Relação das análises de variância (Tabela 2) referentes à primeira semana de vida das aves para as variáveis ambientais: temperatura do ar ( $\mathrm{T}$ ), velocidade do ar (Var) e umidade relativa do ar (UR). Optou-se pelo desdobramento das interações sistemas de ventilação x hora, independentemente de sua significância, fixando o efeito de horário.

Os valores médios observados da temperatura do $\operatorname{ar}(\mathrm{T}) \mathrm{em}$ ${ }^{\circ} \mathrm{C}$, em função dos horários de observação na primeira semana de vida das aves, no interior das instalações experimentais, estão apresentados na Figura 1.
Tabela 2. Resumo das análises de variância verificadas durante a primeira semana de alojamento no ambiente interno das instalações para a temperatura do $\operatorname{ar}\left({ }^{\circ} \mathrm{C}\right)$, velocidade do ar $\left(\mathrm{m} \mathrm{s}^{-1}\right)$, umidade relativa do ar $(\%)$ e índice de temperatura de globo negro e umidade (ITGU)

\begin{tabular}{|c|c|c|c|c|}
\hline \multirow{2}{*}{$\begin{array}{l}\text { Fonte de } \\
\text { variação }\end{array}$} & \multirow[b]{2}{*}{ G.L. } & \multicolumn{3}{|c|}{ Quadrado médio (primeira semana) } \\
\hline & & $\begin{array}{c}\text { Temperatura } \\
\text { do ar }\left({ }^{\circ} \mathrm{C}\right)\end{array}$ & $\begin{array}{l}\text { Velocidade } \\
\text { do ar }\left(\mathrm{m} \mathrm{s}^{-1}\right)\end{array}$ & $\begin{array}{l}\text { Umidade } \\
\text { relativa (\%) }\end{array}$ \\
\hline Tratamento & 2 & $536,07 *$ & $3,045^{\star}$ & $13392,13^{*}$ \\
\hline Dia & 6 & $167,91^{*}$ & $0,013^{\text {ns }}$ & $4719,85^{\star}$ \\
\hline Tratamento $\mathrm{x}$ dia & 12 & $32,42^{*}$ & $0,053^{*}$ & $206,85^{\star}$ \\
\hline Hora & 95 & $279,75^{\star}$ & $0,0016^{\text {ns }}$ & $755,46^{*}$ \\
\hline Tratamento $\times$ hora & 190 & $1,56^{\text {ns }}$ & $0,0016^{*}$ & $13,36^{\text {ns }}$ \\
\hline
\end{tabular}

* significativo em nível de 0,05 de probabilidade, pelo teste $\mathrm{F}$; ${ }^{\star *}$ significativo em nível de 0,05 de

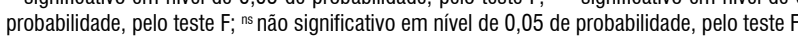

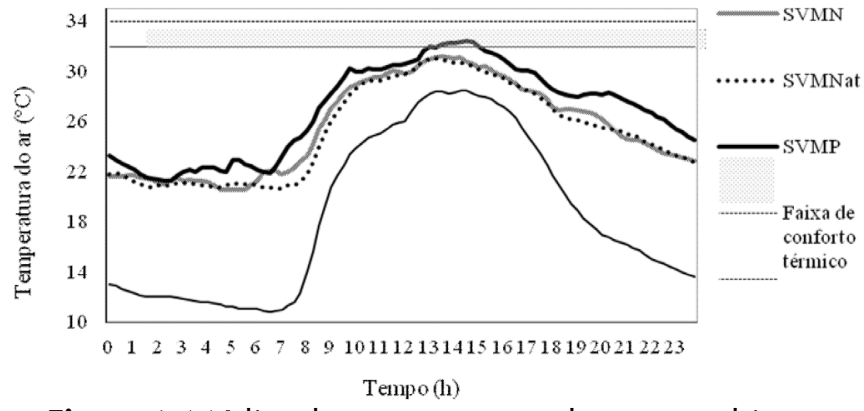

Figura 1. Médias das temperaturas do ar no ambiente interno e externo, no período de 1 a 7 dias de vida das aves, para os três sistemas de ventilação mínima, por pressão negativa (SVMN), por pressão positiva (SVMP) e por via natural (SVMNat) em função do tempo

Segundo Cony \& Zoche (2004), Oliveira et al. (2006) e Pauli et al. (2008), valores de temperatura compreendidos entre $32 \mathrm{e}$ $34^{\circ} \mathrm{C}$ são considerados confortáveis para a primeira semana de vida das aves; essas faixas de níveis ótimos alcançados podem ser observadas na Figura 1.

Segundo os dados médios de temperatura do ar verificados nos sistemas de ventilação mínima SVMN, SVMP e SVMNat, na primeira semana de vida das aves, não foram alcançados níveis satisfatórios aos considerados confortáveis, para nenhum dos três tratamentos. Vigoderis et al. (2010) observaram comportamento semelhante em pesquisas realizadas com sistemas de aquecimento no período do inverno mostrando que em períodos de frio intenso não se tem atingido as condições adequadas de temperaturas, nas primeiras semanas de vida das aves.

Esses resultados podem ser explicados pelo fato de o isolamento dos pinteiros (área de crescimento inicial) ser muito débil, dificultando a manutenção da temperatura do ar dentro das condições de conforto térmico, tanto para as aves como para as pessoas que trabalham neste ambiente (Carvalho et al., 2011).

Sendo assim, níveis de conforto ocorreram apenas por um pequeno intervalo de tempo, somente para o sistema de ventilação mínima por pressão positiva, período este compreendido entre 13 h 30 min e 14 h 45 min (Figura 1). Segundo Carvalho et al. (2011) e Teixeira et al. (2004) este é o horário mais quente do dia em decorrência da maior incidência de radiação solar direta sobre telhados e parâmetros verticais do galpão. 
Observa-se que as amplitudes das curvas de temperatura do ar interno das instalações para todos os sistemas de ventilação mínima, em relação às temperaturas do ambiente externo, se apresentam bem maiores durante o período noturno (o que está de acordo com o esperado, uma vez que este é o período mais frio do ciclo de $24 \mathrm{~h}$ ).

Observa-se, na Figura 2, que os maiores valores de velocidade do ar foram verificados no sistema por pressão positiva, quando se obteve diferença estatística $(\mathrm{P}<0,05)$ em relação aos demais tratamentos, na maioria dos horários observados. Na ventilação natural as médias de velocidade do ar foram muito baixas não sendo, portanto, consideradas níveis adequados para se realizar a mínima renovação de ar e garantir boas condições higiênicas e de qualidade de ar.

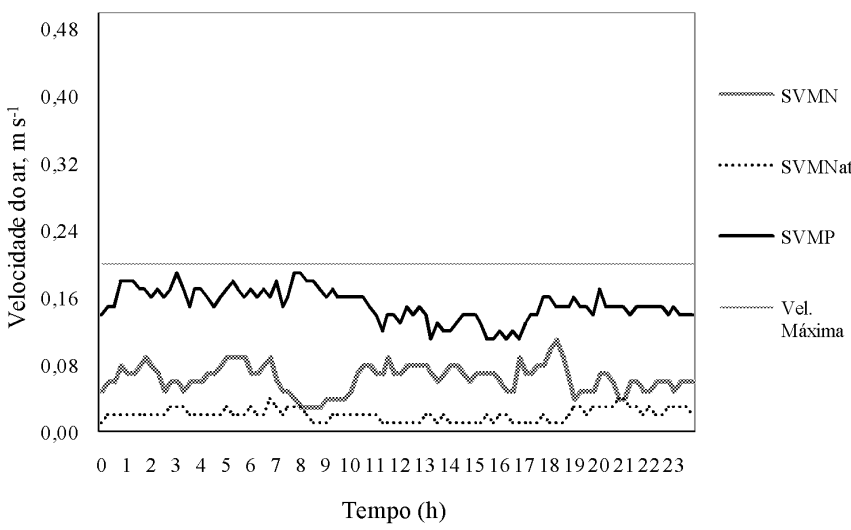

Figura 2. Médias das velocidades do ar no ambiente interno dos aviários, no período de 1 a 7 dias de vida das aves, para os três sistemas de ventilação mínima, por pressão negativa (SVMN), por pressão positiva (SVMP) e por via natural (SVMNat) em função do tempo

Conforme ilustrado na Figura 2, o sistema de ventilação mínima que proporcionou valores de velocidades do ar significativamente maiores e mais adequadas às renovações higiênicas e mais próximas daquelas propostas por $\mathrm{COBB}$ (2008) como ideais para a primeira semana de vida das aves, entre 0,08 a $0,20 \mathrm{~m} \mathrm{~s}^{-1}$, foi o SVMP, seguido do SVMN. No caso do SVMP verifica-se que as velocidades do ar não foram consideradas excessivas para este período de vida das aves uma vez que os níveis de temperatura do ar a nível das aves não foram afetados pelo processo de ventilação, comparativamente aos outros sistemas, ou seja, as maiores temperaturas do ar ocorreram no SVMP apesar de ser o sistema com maior velocidade do ar, a nível das aves.

Verifica-se portanto que, possivelmente, houve falhas no sistema de aquecimento adotado (campânulas a lenha); acredita-se serem devidas ao abastecimento irregular feito pelo trabalhador e pela vedação incorreta das lonas, haja vista que as temperaturas medidas no interior das instalações foram semelhantes nos três sistemas de ventilação mínima.

Esses resultados fazem supor que o problema de baixas temperaturas dos aviários brasileiros, mencionados por Vigoderis et al. (2010) e Cordeiro et al. (2010) tem uma relação muito estreita não só com os sistemas de aquecimento mas muito fortemente com o baixo isolamento térmico dos envoltórios do abrigo.

Os valores médios da umidade relativa do ar (UR) observados em \%, em função dos horários de observação na primeira semana de vida das aves, no interior das instalações, estão apresentados na Figura 3.

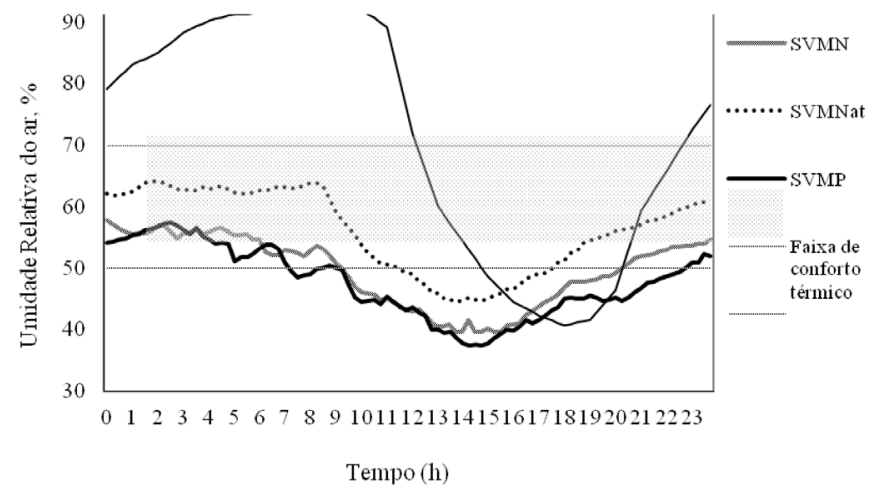

Figura 3. Médias da umidade relativa do ar no ambiente interno e externo, no período de 1 a 7 dias de vida das aves, para os três sistemas de ventilação mínima, por pressão negativa (SVMN), por pressão positiva (SVMP) e por via natural (SVMNat) em função do tempo

De acordo com Medeiros et al. (2005) a faixa ideal de UR deve estar entre 50 e $70 \%$. Na maioria dos horários observados as melhores condições de umidade relativa do ar foram observadas no aviário provido com ventilação mínima natural (SVMNat), diferindo estatisticamente dos demais tratamentos, pelo teste de médias.

Verifica-se, por meio da Figura 3, que as médias de umidade relativa se encontram dentro da faixa considerada adequada para o bom desenvolvimento das aves, em horários compreendidos no período noturno, entre 23 e $7 \mathrm{~h}$, para os três sistemas de ventilação mínima avaliados.

Observa-se, entretanto, que na maioria das horas do dia os valores de umidade relativa do ar estiveram abaixo daqueles considerados favoráveis às condições ótimas de pintos de corte na primeira semana de vida. Condição semelhante foi observada por Cordeiro et al. (2010) em pesquisa conduzida em aviários para frangos de corte no sul do Brasil, no qual verificou que no sistema de aquecimento associado (tambor + fornalha) os valores de umidade relativa permaneceram abaixo de $50 \%$ na maioria dos horários, na primeira semana de vida das aves. Valores de umidade relativa do ar menores que $50 \%$ podem ser danosos aos pintos de corte na sua primeira semana de vida, já que podem levar à desidratação dos animais.

Em função dessas observações infere-se que os sistemas de ventilação mecânica (SVMN e SVMP) apresentaram médias mais baixas de umidade relativa do ar, mantendo o ar mais seco no interior das instalações. Esta ocorrência é justificável devido ao fato de que no SVMN e SVMP os sistemas de ventilação artificial garantem renovação do ar mais controlada e eficiente em relação ao aviário com ventilação natural.

As análises de variância, referentes aos efeitos dos tratamentos para a segunda semana, sistema de ventilação mínima por pressão negativa (SVMN), por pressão positiva 
(SVMP) e ventilação por via natural (SVMNat) e tempo (h) com relação à média horária no interior das instalações para a variável ambiental temperatura do ar $(\mathrm{T})$, umidade relativa do ar (UR) e velocidade do ar, se encontram na Tabela 3.

Tabela 3. Resumo das análises de variância verificadas durante a segunda semana de alojamento no ambiente interno das instalações para a temperatura do $\operatorname{ar}\left({ }^{\circ} \mathrm{C}\right)$, velocidade do $\operatorname{ar}\left(\mathrm{m} \mathrm{s}^{-1}\right)$ e umidade relativa do $\operatorname{ar}(\%)$

\begin{tabular}{|c|c|c|c|c|}
\hline \multirow[b]{2}{*}{$\begin{array}{l}\text { Fonte de } \\
\text { variação }\end{array}$} & \multirow[b]{2}{*}{ G.L. } & \multicolumn{3}{|c|}{ Quadrados médios (segunda semana) } \\
\hline & & $\begin{array}{l}\text { Temperatura } \\
\text { do ar }\left({ }^{\circ} \mathrm{C}\right)\end{array}$ & $\begin{array}{l}\text { Velocidade } \\
\text { do ar }\left(\mathrm{m} \mathrm{s}^{-1}\right)\end{array}$ & $\begin{array}{c}\text { Umidade } \\
\text { relativa (\%) }\end{array}$ \\
\hline Trat & 2 & $741,00 *$ & $2,763^{\star}$ & $8992,76^{\star}$ \\
\hline Dia & 6 & $138,28 *$ & $0,046^{\text {ns }}$ & $1512,28 *$ \\
\hline Trat*Dia & 12 & $10,83^{*}$ & $0,033^{*}$ & $46,33^{*}$ \\
\hline Hora & 95 & $325,48 *$ & $0,0017^{*}$ & $1329,09 *$ \\
\hline Trat*Hora & 190 & $2,14^{*}$ & $0,0020^{*}$ & $30,63^{*}$ \\
\hline
\end{tabular}

* significativo em nível de 0,05 de probabilidade, pelo teste $\mathrm{F}$; ${ }^{* *}$ significativo em nível de 0,01 de probabilidade, pelo teste $F$; ${ }^{\text {ns }}$ não significativo em nível de 0,05 de probabilidade, pelo teste $F$

A interação tratamento $\mathrm{x}$ hora na segunda semana de confinamento das aves foi estatisticamente significativa $(\mathrm{P}<$ $0,05)$ para as variáveis ambientais temperatura, velocidade e umidade relativa do ar.

Os valores médios observados da temperatura do ar (T), em ${ }^{\circ} \mathrm{C}$ e para velocidade do ar, em m s${ }^{-1}$, em função dos horários de observação na segunda semana de vida das aves, no interior das instalações experimentais, estão apresentados nas Figuras 4 e 5.

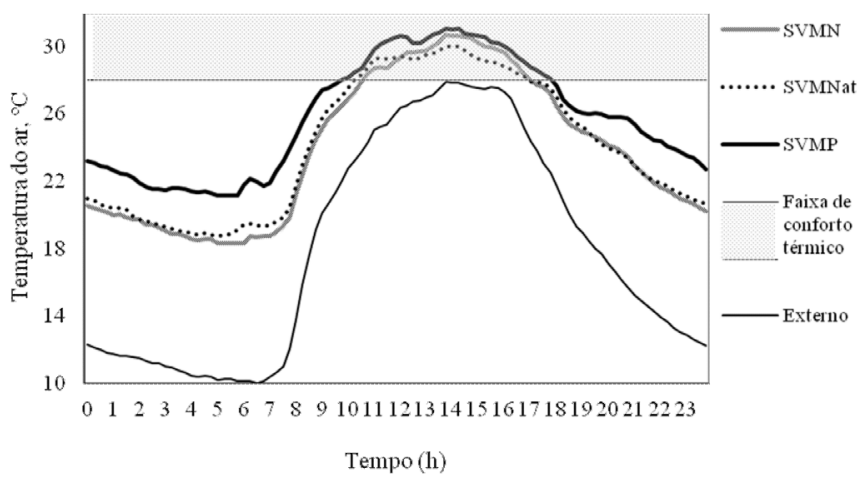

Figura 4. Médias das temperaturas do ar no ambiente interno e externo, no período de 8 a 14 dias de vida das aves, para os três sistemas de ventilação mínima, por pressão negativa (SVMN), por pressão positiva (SVMP) e por via natural (SVMNat) em função do tempo

As faixas de temperatura são consideradas de conforto térmico para a segunda semana de vida das aves, compreendidas entre 30 e $32^{\circ} \mathrm{C}$ conforme Cony \& Zoche (2004) e Ávila (2004) e as velocidades do ar entre 0,15 e $0,3 \mathrm{~m} \mathrm{~s}^{-1}$.

Conforme dados apresentados na Figura 4 de que as médias de temperatura sob as quais as aves ficaram expostas durante a segunda semana de vida, estiveram bem abaixo do nível de conforto considerado. Por meio da Figura 4 verifica-se que os níveis satisfatórios foram observados entre período de tempo de 10 h 45 min e 16 h 45 min para os três sistemas SVMN, SVMNat e SVMP. Menegali et al. (2009) e Vigoderis et al. (2010) observaram comportamento semelhante em condições de inverno no sul do Brasil; entre o período de 12 h e $30 \mathrm{~min}$

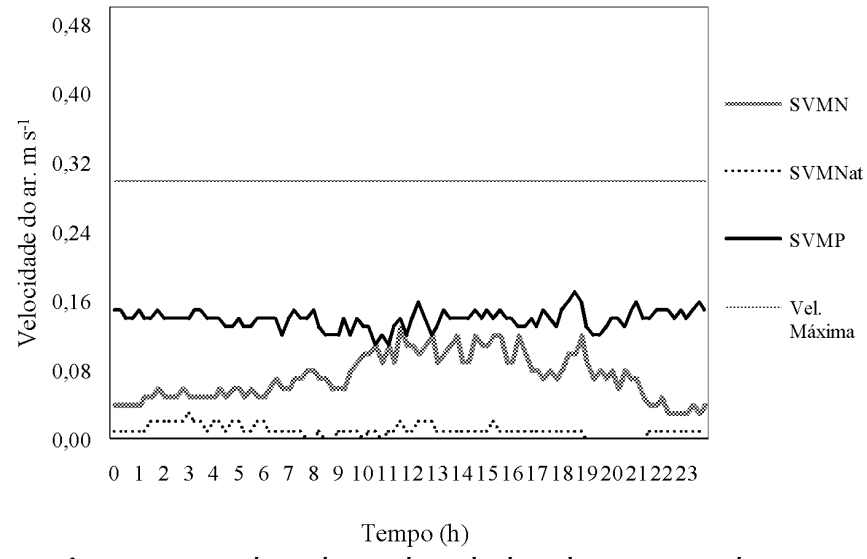

Figura 5. Médias das velocidades do ar no ambiente interno, no período de 8 a 14 dias de vida das aves, para os três sistemas de ventilação mínima, por pressão negativa (SVMN), por pressão positiva (SVMP) e por via natural (SVMNat) em função do tempo

e 20 h e 45 min, não se obteve diferença estatística entre os tratamentos $(\mathrm{P}<0,05)$.

Apesar de não ter apresentado níveis satisfatórios durante o período observado em relação aos horários, o sistema SVMP obteve, em sua maioria, diferença estatística em relação aos demais principalmente no período noturno, em poucas horas da manhã entre 21 h e 9 h 45 min, com níveis mais altos de temperatura que os demais.

Verificando as amplitudes na curva de temperatura do ar observa-se que são amplitudes térmicas amplas e que o sistema SVMNat apresentou máxima de $30,0{ }^{\circ} \mathrm{C}(13 \mathrm{~h}$ e $45 \mathrm{~min})$ e mínima $18,8^{\circ} \mathrm{C}(5 \mathrm{~h})$ e no SVMN a máxima foi de $30,7^{\circ} \mathrm{C}(13 \mathrm{~h}$ e $45 \mathrm{~min}$ ) e mínima de $18,3^{\circ} \mathrm{C}$ ( $05 \mathrm{~h}$ e $30 \mathrm{~min}$ ) proporcionando amplitudes de 11,3 e $12,4^{\circ} \mathrm{C}$, respectivamente, no interior das instalações.

Menegali et al. (2009) relatam que na fase inicial de vida das aves a exposição a temperatura ambiente abaixo de $10^{\circ} \mathrm{C}$ pode interferir no desempenho das aves além de estar relacionada ao aparecimento de doenças metabólicas, como ascite e síndrome de morte súbita.

Na Figura 5 se encontram, relacionados, os resultados dos valores médios de velocidade do ar observados no interior das instalações referentes à segunda semana, correspondendo aos tratamentos (SVMN, SVMNat e SVMP).

Com base na Figura 5, observa-se que o sistema mais eficiente de ventilação para a segunda semana de vida das aves, novamente como ocorrido também na primeira semana, foi o SVMP, e a taxa de velocidade do ar incidida para os sistemas de SVMP e SVMN apresentaram seus valores muito próximos entre os horários de 10 e $12 \mathrm{~h}$, com maior amplitude entre os sistemas verificados no período entre $20 \mathrm{e} 9 \mathrm{~h}$; assim, é provável que tenha ocorrido falha no sistema de aquecimento, sobretudo durante o período noturno.

Bakker (2005) considera, para a segunda semana, velocidades máximas para a realização da ventilação mínima de $0,15 \mathrm{~m} \mathrm{~s}^{-1}$; observa-se, então, que as melhores velocidades do ar foram verificadas no sistema SVMP que estiveram muito próximo das ideais. 
Para a umidade relativa níveis adequados de produção se apresentam na faixa entre 50 e $70 \%$. Em todo o período compreendido entre 18 às $10 \mathrm{~h} \mathrm{e} 45 \mathrm{~min}$, as condições internas de umidade relativa se mantêm na faixa de conforto para os três tratamentos de ventilação SVMN, SVMP e SVMNat porém com os melhores índices verificados no sistema natural (SVMNat) com diferença estatística pelo teste de Tukey (P $<$ $0,05)$ na maioria dos horários em relação aos demais sistemas observados.

Observa-se, através da Figura 6, que os três sistemas apresentaram comportamentos semelhantes em relação ao tempo com pequena discrepância dos sistemas em relação à externa.

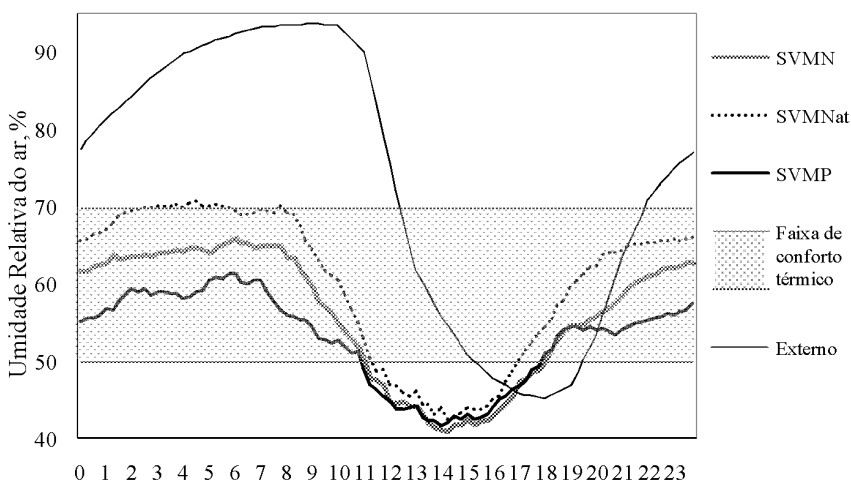

Tempo (h)

Figura 6. Média da umidade relativa do ar no ambiente interno e externo, no período de 8 a 14 dias de vida das aves, para os três sistemas de ventilação mínima, por pressão negativa (SVMN), por pressão positiva (SVMP) e por via natural (SVMNat) em função do tempo

As médias mínimas de UR interna foram verificadas em torno de $14 \mathrm{~h}$, para os três tratamentos, como previsto, pois são inversamente proporcionais às médias de temperatura que atinge seus valores máximos neste mesmo período de tempo, caso em que a curva de tendência da UR externa atinge seus valores mínimos em torno de $18 \mathrm{~h}$, o que não é comum de se encontrar, identificando-se um atraso em relação às encontradas no interior das instalações.

Apesar das adversidades climáticas externas com noites muito frias e dia mais ameno, houve uma estabilidade da variável UR interna em relação aos sistemas avaliados apresentando, por um amplo período de tempo, médias dentro da faixa ideal de conforto, deixando o ambiente com ar mais seco no período entre 11 e $17 \mathrm{~h}$, com valores mais baixos que os desejados para esta semana de vida das aves.

As análises de variância para a terceira semana referentes aos efeitos dos tratamentos e das horas (h) em relação à média horária no interior das instalações para as variáveis ambientais, se encontram na Tabela 4.

A interação tratamento $\mathrm{x}$ hora na terceira semana de confinamento das aves foi estatisticamente significativa $(\mathrm{P}<$ $0,05)$ apenas para a variável velocidade do ar. Para as variáveis ambientais temperatura e umidade relativa do ar, não foi significativa pelo teste F. Conforme Cony \& Zoche (2004) e
Tabela 4. Resumo das análises de variância verificadas durante a terceira semana de alojamento no ambiente interno das instalações para a temperatura do $\operatorname{ar}\left({ }^{\circ} \mathrm{C}\right)$, velocidade do $\operatorname{ar}\left(\mathrm{m} \mathrm{s}^{-1}\right)$ e umidade relativa do $\operatorname{ar}(\%)$

\begin{tabular}{lrccc}
\hline \multirow{2}{*}{$\begin{array}{l}\text { Fonte de } \\
\text { variação }\end{array}$} & G.L. & \multicolumn{2}{c}{ Quadrados médios (terceira semana) } \\
\cline { 3 - 5 } & 2 & $\begin{array}{c}\text { Temperatura } \\
\text { do ar }\left({ }^{\circ} \mathbf{C}\right)\end{array}$ & $\begin{array}{c}\text { Velocidade } \\
\text { do ar }\left(\mathbf{m ~ s}^{-1}\right)\end{array}$ & $\begin{array}{c}\text { Umidade } \\
\text { relativa (\%) }\end{array}$ \\
Trat & 2 & $454,15^{*}$ & $3,070^{*}$ & $4675,89^{*}$ \\
Dia & 6 & $338,10^{*}$ & $0,053^{*}$ & $1005,12^{*}$ \\
Trat*Dia & 12 & 17,37 & $0,017^{*}$ & $42,41^{*}$ \\
Hora & 95 & $508,00^{*}$ & $0,0030^{*}$ & $2991,45^{*}$ \\
Trat*Hora & 190 & $1,04^{\text {ns }}$ & $0,0022^{*}$ & $15,23^{\text {ns }}$ \\
\hline
\end{tabular}

* significativo em nível de 0,05 de probabilidade, pelo teste $\mathrm{F} ;$ ** significativo em nível de 0,01 de probabilidade, pelo teste $\mathrm{F}$; ns não significativo em nível de 0,05 de probabilidade, pelo teste $\mathrm{F}$

Ávila (2004) as faixas de temperatura consideradas ideais para esta fase, estão compreendidas entre 26 e $28^{\circ} \mathrm{C}$.

$\mathrm{Na}$ Figura 7 observa-se que as temperaturas externas às instalações caracterizaram as horas do dia (entre 10 e $18 \mathrm{~h}$ ) com altas temperaturas durante o dia e noites frias com temperaturas médias entre 11 e $12{ }^{\circ} \mathrm{C}$, ou seja, grandes amplitudes térmicas apresentadas externamente. Considerando a terceira semana de vida das aves, o comportamento da curva de dados médios para os tratamentos SVMN, SVMNat e SVMP foi semelhante entre si e ainda em relação às temperaturas externas porém com a diferença de amortecimento das adversidades externas que foram protegidas pelas instalações.

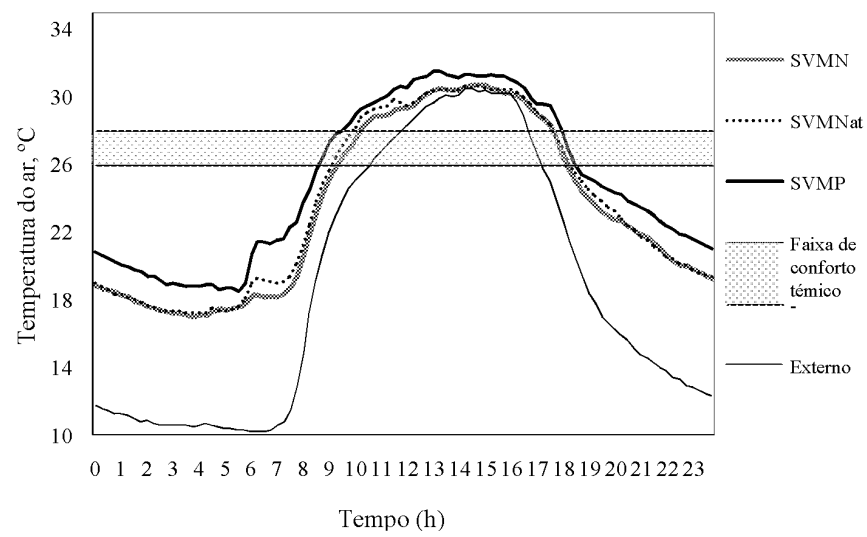

Figura 7. Médias das temperaturas do ar no ambiente interno e externo, no período de 15 a 21 dias de vida das aves, para os três sistemas de ventilação mínima, por pressão negativa (SVMN), por pressão positiva (SVMP) e por via natural (SVMNat) em função do tempo

De acordo com Bakker (2005) e COBB (2008) para a terceira semana de vida das aves as velocidades máximas do ar devem estar no máximo a $0,5 \mathrm{~m} \mathrm{~s}^{-1}$, as médias apresentadas na Figura 8 mostram que as velocidades ficaram aquém do limite máximo sendo que valores superiores poderiam permitir uma eficiência melhor dos sistemas de ventilação mínima sendo que nesta fase os valores entre 50 e $70 \%$ são considerados de conforto para as aves.

Observa-se na Figura 9, entre 23 e 9 h e $30 \mathrm{~min}$, que o sistema SVMNat manteve uma umidade superior a $70 \%$ acima, portanto, da faixa de conforto que, segundo as recomendações, deve ficar entre 50 e 70\% (Tinôco, 2001; Baêta \& Souza, 2010) 


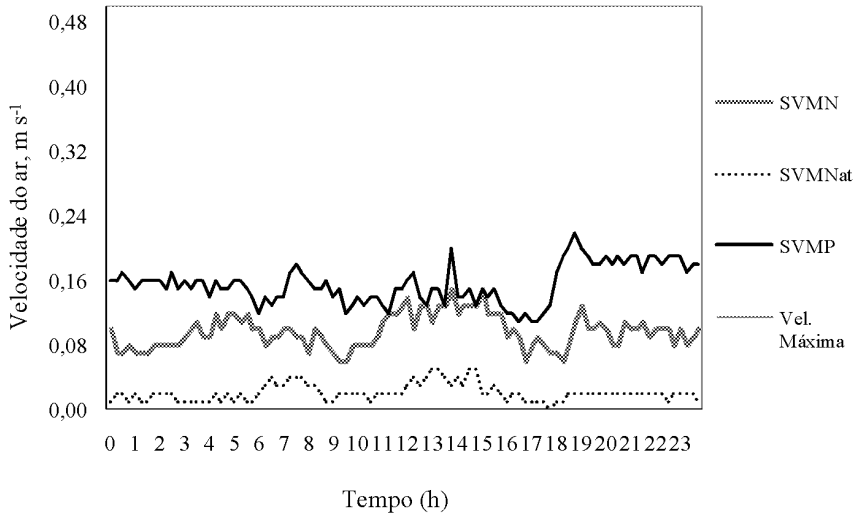

Figura 8. Médias de velocidade do ar no ambiente interno, no período de 15 a 21 dias de vida das aves, para os três sistemas de ventilação mínima, por pressão negativa (SVMN), por pressão positiva (SVMP) e por via natural (SVMNat) em função do tempo

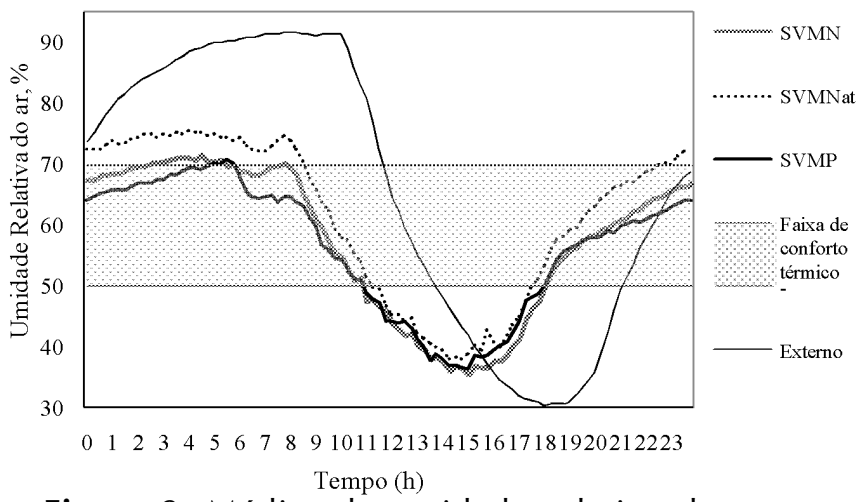

Figura 9. Médias de umidade relativa do ar no ambiente interno e externo, no período de 15 a 21 dias de vida das aves, para os três sistemas de ventilação mínima, por pressão negativa (SVMN), por pressão positiva (SVMP) e por via natural (SVMNat) em função do tempo

apresentando diferença estatística entre os mesmos; no entanto, no período mais quente do dia os valores de umidade relativa estiveram abaixo das condições de conforto térmico.

Para os sistemas de ventilação mecânica SVMN e SVMP, entre 18 às $11 \mathrm{~h}$ a umidade relativa se manteve dentro da zona de conforto térmico sendo que as maiores taxas observadas no sistema SVMNat, podem ser justificadas pela menor taxa de ventilação aplicada, não ocorrendo a renovação necessária para o ambiente, elevando a umidade relativa do ar nos horários com temperaturas mais baixas.

\section{CONCLusõES}

1. Para manter as condições higiênicas do ar interno não ocorreram influências negativas em relação às taxas de ventilação aplicadas para os dois sistemas SVMN e SVMP e com velocidade do ar em níveis não estressores aos pintinhos, inclusive para o SVMNat.

2. O ambiente térmico foi caracterizado como desconfortável para as aves nas três semanas avaliadas, principalmente no período noturno, submetendo-as ao estresse por frio.

\section{Agradecimentos}

À Coordenação de Aperfeiçoamento de Pessoal de Nível Superior (CAPES), ao Conselho Nacional de Desenvolvimento Científico e Tecnológico (CNPq), à Fundação de Amparo à Pesquisa do Estado de Minas Gerais (FAPEMIG) e à Universidade Federal de Viçosa (UFV).

\section{LITERATURA CITADA}

Abreu, P. G.; Abreu, V. M. N. Caracterização dos sistemas de aquecimento para aves. Concórdia: Embrapa CNPSA, 2002. 10p. Comunicado Técnico, 21

Ávila, V. S. Aspectos importantes a considerar na criação de frangos de corte no período frio. Versão eletrônica, 2004. http// www.cnpsa.embrapa.br. 10 Out. 2007.

Baêta, F. C.; Souza, C. F. Ambiência em edificações rurais Conforto animal. Viçosa: UFV, 2010. 269p.

Bakker, W. Minimum ventilation to maximize broiler farm performance. In: Caribbean Poultry Association Poultry \& Egg School, 2005, St Augustine. <http://www.caribbeanpoultry. org/docs/2005/egg_2005/CPAPoultry\&EggSch2005Poultry_WBakker_MinimumVentilation.pdf.>. 9 Jan. 2009.

Banhazi, T. M.; Seedorf, J.; Laffrique, M.; Rutley, D. L. Identification of the risk factors for high airborne particle concentrations in broiler buildings using statistical modeling. Biosystems Engeneering, v.101, p.100-110, 2008.

Carvalho, C. C. S.; Souza, C. F.; Tinôco, I. de F. F.; Vieira, M. F. A.; Minette, L. J. Segurança, saúde e ergonomia de trabalhadores em galpões de frangos de corte equipados com diferentes sistemas de abastecimento de ração. Engenharia Agrícola, v.31, p.438-447, 2011.

COBB - Cobb Vantress Brasil Ltda. Broiler management guide. Arkansas: Cobb-Vantress. 2008. 65p.

Cony, A. V.; Zocche, A. T. Manejo de frangos de corte. Produção de frangos de corte. (ed.). Mendes, A.; Nääs, I. de A.; Macari, M. Campinas: FACTA, 2004. 356p.

Cordeiro, M. B.; Tinôco, I. de F. F.; Mesquita Filho, R. M. de; Sousa, F. C. de. Análise de imagens digitais para a avaliação do comportamento de pintainhos de corte. Engenharia Agrícola, v.31, p.418-426, 2011.

Cordeiro, M. B.; Tinôco, I. de F. F; Silva, J. N.; Vigoderis, R. B. Conforto térmico e desempenho de pintos de corte submetidos a diferentes sistemas de aquecimento no período de inverno. Revista Brasileira de Zootecnia, v.39, p.217-224, 2010.

Martin, S.; Silva, J. N.; Tinôco, I. de F. F.; Vieira, A. C.; Zanatta, F. L.; Melo, L. D. Projeto e construção de um gaseificador de biomassa de fluxoconcorrente. Revista Engenharia na Agricultura, v.14, p.238-249, 2006.

Medeiros, C. M.; Baêta, F. C.; Oliveira, R. F. M.; Tinôco, I. de F. F.; Albino, L. T.; Cecon, P. R. Efeitos da temperatura, umidade relativa e velocidade do ar em frangos de corte. Revista Engenharia na Agricultur a, v.13. p.277-286, 2005. Menegali, I.; Tinôco, I. de F. F.; Baêta, F. C.; Cecon, P. R.; Guimarães, M. C. C; Cordeiro, M. B. Ambiente térmico e concentração de gases em instalações para frangos de corte no período de aquecimento. Revista Brasileira de Engenharia Agrícola e Ambiental, v.13, p.984-990, 2009. 
Oliveira, R. F. M.; Donzele, J. L.; Abreu, M. L. T.; Ferreira, R. A.; Vaz, R.; Gomes, M. V.; Cella, P. S. Efeitos da temperatura e da umidade relativa sobre o desempenho e o rendimento de cortes nobres de frangos de corte de 1 a 49 dias de idade. Revista Brasileira Zootecnia, v.35, p.797-803, 2006.

Pauli, D. G.; Silva, J. N.; Vigoderis, R. B.; Tinôco, I. de F. F. Desenvolvimento de um Sofware para dimensionamento de sistemas de ventilação e resfriamento evaporativo em instalações avícolas climatizadas. Engenharia na Agricultura, v.16, p.167-179, 2008.

Santos, P. A.; Baêta, F. C.; Tinôco, I. de F. F.; Albino, L. F. T.; Cecon, P. R. Avaliação dos sistemas de aquecimento a gás e a lenha para frangos de corte. Revista Ceres, v.56, p.9-17, 2009.

Saraz, J. A. O. ; Tinôco, I. F. F.; Paula, M. O.; Peixoto, R. F ; Gates, R. . Elaboración y evaluación de tejas de concreto en arcilla expandida para uso como coberturas de estructuras pecuarias. Revista Facultad Nacional de Agronomia, v.63, p.5651-5660, 2010.
Teixeira, V. H.; Teixeira, A. S.; Lopes, S. P. Efeito do resfriamento adiabático evaporativo e da ventilação forçada no desempenho de porcas lactantes e suas leitegadas. Revista Engenharia na Agricultura, v.12, p.51-56, 2004.

Tinôco, I. F. F. Avicultura industrial: Novos conceitos de materiais, concepções e técnicas construtivas disponíveis para galpões avícolas brasileiros. Revista Brasileira de Ciência Avícola, v.3, p.1-26, 2001.

Vigoderis, R. B.; Cordeiro, M. B.; Tinôco, I. de F. F.; Menegali, I.; Souza Júnior, J. P.; Holanda, M. C. R. Avaliação do uso de ventilação mínima em galpões avícolas e de sua influência no desempenho de aves de corte no período de inverno. Revista Brasileira de Zootecnia, v.39, p.13811386, 2010.

Zanatta, F. L.; Silva, J. N.; Oliveira Filho, D.; Martin, S. Avaliação do conforto térmico em aviário aquecido com gaseificador de biomassa. Revista Engenharia na Agricultura, v.16, p.270-284, 2008. 